\title{
Perceptions of New Zealand nutrition labels by Māori, Pacific and low-income shoppers
}

\author{
Louise Signal ${ }^{1, *}$, Tolotea Lanumata ${ }^{2}$, Jo-Ani Robinson ${ }^{1}$, Aliitasi Tavila ${ }^{3}$, Jenny Wilton ${ }^{1}$ \\ and Cliona Ni Mhurchu ${ }^{4}$ \\ 'Department of Public Health, Wellington School of Medicine and Health Sciences, University of Otago, PO Box \\ 7343, Wellington South, New Zealand: ${ }^{2}$ Roy McKenzie Centre for the Study of Families, Victoria University, \\ Wellington, New Zealand: ${ }^{3}$ Health Services Research Centre, Victoria University, Wellington, New Zealand: \\ ${ }^{4}$ Clinical Trials Research Unit, University of Auckland, Auckland, New Zealand
}

Submitted 15 January 2007: Accepted 13 September 2007: First published online 2 January 2008

\begin{abstract}
Background: In New Zealand the burden of nutrition-related disease is greatest among Māori, Pacific and low-income peoples. Nutrition labels have the potential to promote healthy food choices and eating behaviours. To date, there has been a noticeable lack of research among indigenous peoples, ethnic minorities and lowincome populations regarding their perceptions, use and understanding of nutrition labels. Our aim was to evaluate perceptions of New Zealand nutrition labels by Māori, Pacific and low-income peoples and to explore improvements or alternatives to current labelling systems.

Methods: Māori, Samoan and Tongan researchers recruited participants who were regular food shoppers. Six focus groups were conducted which involved 158 people in total: one Māori group, one Samoan, one Tongan, and three low-income groups. Results: Māori, Pacific and low-income New Zealanders rarely use nutrition labels to assist them with their food purchases for a number of reasons, including lack of time to read labels, lack of understanding, shopping habits and relative absence of simple nutrition labels on the low-cost foods they purchase.

Conclusions: Current New Zealand nutrition labels are not meeting the needs of those who need them most. Possible improvements include targeted social marketing and education campaigns, increasing the number of low-cost foods with voluntary nutrition labels, a reduction in the price of 'healthy' food, and consideration of an alternative mandatory nutrition labelling system that uses simple imagery like traffic lights.
\end{abstract}

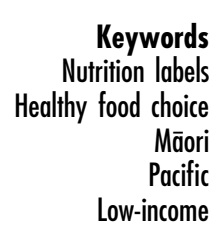

Making healthy food choices is critical to maintaining health. Approximately $40 \%$ of deaths in New Zealand are due to the joint effects of high cholesterol levels, high blood pressure, obesity, and inadequate fruit and vegetable intake ${ }^{(1,2)}$. Poor nutrition is a major determinant of health inequalities: $47 \%$ of deaths among Māori are attributable to nutrition-related risk factors compared with 39\% among non-Māori (3). Similarly, Pacific and Asian New Zealanders have increased rates of nutritionrelated conditions such as obesity ${ }^{(4,5)}$ compared with New Zealand Europeans. There are also well-known ethnic and socio-economic disparities in rates of nutrition-related diseases such as CVD ${ }^{(6,7)}$. Despite this, there is a noticeable lack of research internationally regarding perceptions and use of nutrition labels among indigenous people, ethnic minority and low-income populations ${ }^{(8,9)}$. It is essential to ensure that those populations who suffer the greatest burden of nutrition-related disease can effectively use nutrition labels, yet only two studies have evaluated the prevalence of nutrition label use among ethnic minorities.

A programme to encourage healthy food choices in supermarkets in predominantly African American communities in Detroit used colour-coded shelf labels (green for 'best choice' and yellow for 'acceptable choice') to identify food items low in total fat, saturated fat, cholesterol and sodium ${ }^{(10)}$. A survey conducted among 361 shoppers leaving participating supermarkets found that $29 \%$ were aware of the programme. Among those aware of the programme, 39\% said they used it 'a little' or 'sometimes', while $17 \%$ used it 'often' or 'always'. Selfreported prevalence of nutrition label use and associations with diet were also measured in a survey of 658 African Americans in North Carolina ${ }^{(11)}$. Less than half ( $46 \%$ ) of respondents reported using nutrition labels 'usually' or 'often'.

Research involving 181 low-income shoppers found that overall $35-45 \%$ seldom/never read labels while 
shopping ${ }^{(12)}$. The authors hypothesise that this was due to lack of perceived benefit in using labels since, when tested, study participants generally appeared competent in performing tasks using the label. A further small study based on focus group discussions with eight low-income food shoppers found a general lack of understanding of nutrition label components ${ }^{(13)}$. This lack of understanding was compounded by other perceived barriers to buying healthy foods such as restricted food budgets. Although these studies suggest that low-income shoppers may have lower use and understanding of nutrition labels, another study among 919 low-income shoppers found that reported use of nutrition labels was significantly associated with improved dietary quality ${ }^{(14)}$, suggesting that there is an association between label use and dietary quality although the direction of this effect cannot be determined.

In 2002 nutrition labelling became mandatory for all manufactured foods sold in New Zealand. Standardised Nutrition Information Panels (NIP) for eligible foods are required to provide information on levels of energy, protein, total fat, saturated fat, carbohydrate, sugars and sodium, as well as any other nutrient about which a claim is made on the label (Fig. 1).

The New Zealand National Heart Foundation (NHF) also coordinates a voluntary endorsement 'Pick the Tick' nutrition labelling programme that provides a framework for cooperation with the food industry to improve nutrition labelling and develop a healthy food supply, and a guide to healthy food choices for consumers. It has, for example, been successful in reducing salt in endorsed food products sold in New Zealand ${ }^{(15)}$. Consumer research conducted by the NHF in 2005 found that $73 \%$ of main grocery buyers claim to use the Tick 'regularly' or 'sometimes, (16).

Defined nutritional criteria are set by the NHF for the saturated fat, total fat, sodium, added sugar, calcium and fibre contents of food products. Food manufacturers whose products meet the criteria enter into a formal licensing agreement with the NHF, which enables them to display the Tick logo on the packaging of approved products (Fig. 1). To date, some 950 pre-packed products

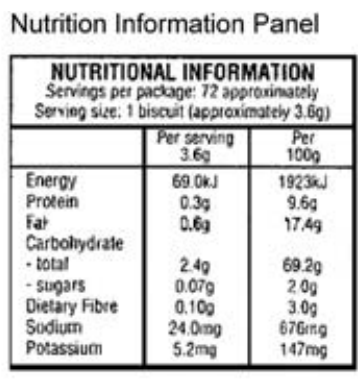

Multiple traffic light logo

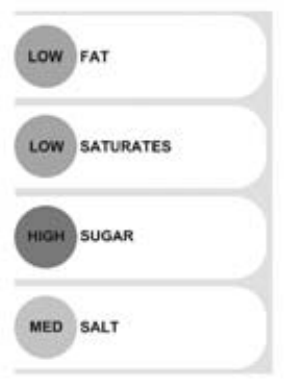

Tick plus Pyramid logo

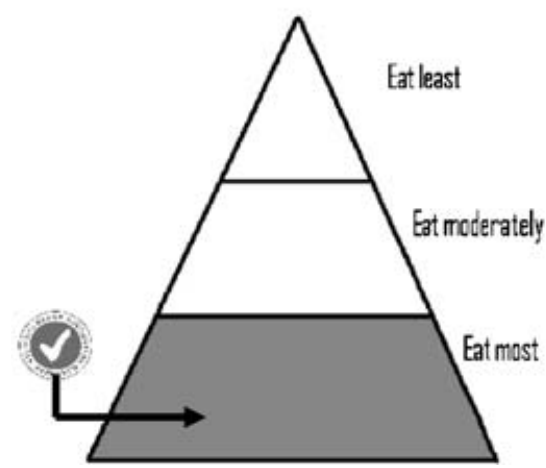

\section{NHF Tick logo}

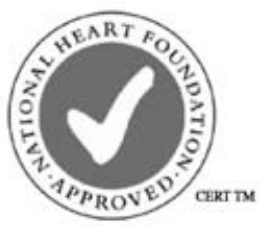

Simple traffic light logo

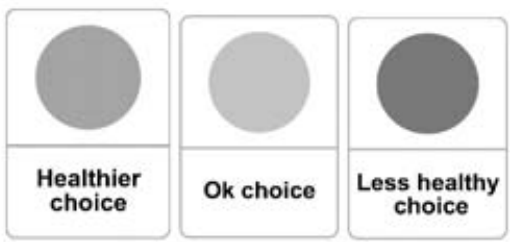

Multilingual Tick logo

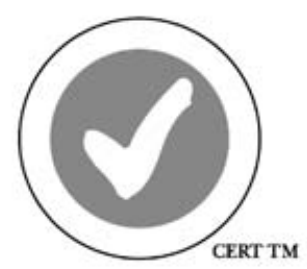

National Heart Foundation approved

Te Hotu Manawa Whainui whakapaitia

Pacific Island Heartbeats Programme approved

Fig. 1 Nutrition labels used in the focus group discussions 
from more than sixty manufacturers have been endorsed $^{(17)}$. Because participation is voluntary, the logo only appears on a select number of foods rather than on all potentially eligible foods.

The aims of the present research were to determine:

1. Are Māori, Pacific and low-income peoples aware of New Zealand nutrition labels, what are their attitudes to them, and do they use them to guide food choices?

2. What improvements could be made to current labels, or alternatives put in place, to meet the needs of Māori, Pacific and low-income peoples?

\section{Methods}

\section{Research design and data analysis}

Six focus groups were conducted in the Wellington region of New Zealand. A Māori researcher facilitated the Māori and low-income groups; a Samoan researcher facilitated the Samoan group; and a Tongan researcher facilitated the Tongan group. A questionnaire was developed jointly by the researchers to ensure the appropriateness of the questions for all groups and translated into Māori, Samoan or Tongan as required (Table 1). The focus groups explored the participants' knowledge and use of the NIP that is mandatory on packaged food in New Zealand, their knowledge and use of the NHF 'Pick the Tick' programme, and alternative food labelling options including traffic lights and a food pyramid similar to one used previously in New Zealand (Fig. 1).

Focus group sessions were tape-recorded with the consent of the participants. The three researchers transcribed the key findings from each focus group and analysed them according to the research questions and the key themes that emerged. The research team met to discuss the findings. The draft report was peer-reviewed by the research team to ensure the views of each of the communities were reflected appropriately. An advisory group of Māori, Pacific and European nutrition experts provided advice throughout the project.

\section{Participants}

Twelve women participated in the Māori focus group, a number of whom were teenage mothers. There were thirteen participants in the Tongan group: three men and ten women. All were Tongan except one who was both Tongan and Māori. Twelve people, nine women and three men, attended the Samoan focus group, the majority of whom were aged between 45 and 70 years. There were 121 participants altogether in the three lowincome groups. There were more women than men and they ranged in age from teenage to retirement age. All low-income participants were beneficiaries or selfidentified as low-income. The researchers recruited participants who were regular food shoppers via their community networks, which included church networks and contacts in low-income council housing.

\section{Results}

\section{Low-income people}

Nutrition labels and Nutrition Information Panels

The majority of low-income participants had seen nutrition labels on food packaging. A number of participants were able to explain that nutrition labels provide details

Table 1 Questions from the focus group questionnaire on nutrition labels (to be translated into Māori, Samoan and Tongan)

1. Have you seen nutrition information on food packages? If so, could you describe it for me?

2. Do you use nutrition information on food packaging to help you decide what to buy? Why/why not? Food labels

3. [Show nutrition panel on the flipchart and product with a nutrition panel on it] Have you heard of or seen labels like this on food packaging?

4. What does it mean to you?

5. What do you think of it? [Prompts: language, colour, symbol, how easy is it to understand?]

6. Now I would like to find out if you use food labels like this to help you decide what to buy. I would like to know whether you never, occasionally or often use food labels. Could we have a show of hands:

(a) How many people never use food labels to help decide what to buy?

(b) How many people occasionally use food labels to help decide what to buy?

(c) How many people often use food labels to help decide what to buy?

7. Why or why don't you use food labels? [Prompts: cost, language, time, do you use food labels when you have an illness, knowledge about food labels]

Alternatives

8. If you were asked to design a healthy food label for your community what would it look like?

9. Why would you design it this way? [Prompts: language, colour, symbol, how easy is it to understand?]

10. [Show people each different food labelling option in turn, e.g. traffic light system, simple traffic light system, food pyramid, bilingual tick] Ask participants about each logo:

(a) What does it mean to you?

(b) What do you think of it? [Prompts: language, colour, symbol, how easy is it to understand?]

(c) If you could, would you make any changes to it?

11. Which label would you most like to see on a food package? Why?

12. Can you think of other ways to let the community know about healthy food in the supermarket? [Prompts: sections of the supermarket marked in some way]

13. Do you have any questions? 
about nutrient levels, e.g. 'It means how much fat you have in it'. However, the majority were unaware of what nutrition labels meant and the NIP in particular was perceived as hard to understand. The main reasons for not using nutrition labels were lack of understanding and the perceived cost of healthy food. One participant commented, 'If something is good for your health we can't buy it'. Only $3 \%$ of low-income participants reported using the NIP 'often' to help decide what to buy, $17 \%$ used them 'occasionally' and $80 \%$ 'never' used them. There was a common view that people tend to buy what they know when food shopping, which for low-income people means buying the cheaper brands with little attention being paid to nutrition label information.

\section{The National Heart Foundation Tick logo}

Nearly all low-income participants had seen the Tick logo and knew about it from a range of places, including advertisements, supermarkets, family doctors, dietitians and from their children. There was a range of responses regarding what the Tick logo means. A number of people stated that the Tick logo represents something 'Good for your health', 'Good for your heart' or 'Healthy food to buy'. Others felt that the Tick logo 'looks healthy' and is easy to understand. However, still others did not look for the logo or did not know what it meant. The size of the Tick logo was identified as a problem and a number of participants said that the Tick ought to be bigger so it is easier to read.

Despite the fact that many participants recognised the Tick logo and some were able to explain its meaning, $90 \%$ reported 'never' using the Tick to guide food choices. One of the main barriers to using the Tick was cost: the Tick does not appear on many of the cheaper brands the participants buy. Other barriers were lack of understanding around what the Tick meant and also lack of time to look for Tick products in the supermarket. There was some confusion about whether products that do not carry the Tick were healthy or not. A number of participants felt that products without the Tick were inferior and '...not good enough to eat - we will all die 'cause we can't afford to buy [the Tick]'.

\section{Alternative labels}

Participants were asked for alternative ideas for a healthy food label. There was general support for keeping it simple and for using pictures instead of words, as some people cannot read well. Participants preferred nutrition labels to have bright colours, well-known symbols and to be multilingual. Overall participants preferred the multiple traffic light system of the alternatives presented because traffic lights are well known and therefore easily understood. However, there was concern that technical language may act as a barrier (e.g. saturates). There was little support for the food pyramid with comments such as
'It means nothing'. The majority of people still expressed concern that any system would fail them: 'At the end of the day you do the same old thing 'cause that's all you can afford'.

\section{Māori}

\section{Nutrition labels and Nutrition Information Panels}

Māori participants identified a range of nutrition labels they had seen on food products, including the Tick. All had seen the NIP on food products. Some knew that the NIP provides information about what is in a product and also about what is in a serving size. Other participants said the NIP means nothing to them and found the numeric nature of the label confusing. Only one Māori participant used the NIP occasionally to help buy appropriate foods in response to allergies and illness. The other eleven participants never used the panel. The main reason given was that many did not have time to read labels in the supermarket, especially if they had young children with them. Many also found the labels too hard to understand. The perceived cost of healthy nutritious foods was also identified as an issue: there was a sense within the group that healthy foods are more expensive and therefore looking at nutrition labels is a waste of time. Many in the group said they bought the foods they had grown up with and some felt they did not have sufficient knowledge about which foods are healthy.

\section{The National Heart Foundation Tick logo}

All twelve participants had seen the Tick logo. Participants had heard of or seen the Tick on television, in supermarkets and at doctors' surgeries. Two participants stated that the Tick logo is on healthier foods and one added, 'It's good for your heart'. Two participants thought the Tick logo was simple and easy to understand but two suggested that it should be bigger so it can be easily read. Participants seemed to realise that products with the Tick should be eaten in moderation, depending on what the product is.

While there was some support for the concept of the Tick, ten of the twelve participants did not use the Tick at all. Participants repeated that they could not afford to buy healthy foods. One knew that the Tick is largely not on low-cost products, which many of the participants buy. One was unsure whether the Tick logo was intended for young people, or just for people with heart problems. Overall, participants felt that if a product does not carry the Tick it is cheaper to buy and also less healthy for you.

\section{Alternative labels}

Participants wanted labels to be bright, simple and big, so that they stand out and are easy to see. Some felt that the Tick used by the NHF was a judgement on their behaviour (i.e. if they could not afford to buy Tick 
products they had failed yet again) and so preferred a more neutral symbol. The multiple traffic light labels met with support as the colours are well known; however the word 'saturates' was not well understood. The simple traffic light label was preferred to the multiple traffic light label because its simplicity would make it less time-consuming to use. Some participants expressed concern that they would only be able to afford products carrying a red light and that manufacturers would not want this system if all their products fell into the 'red' category. The researchers raised the possibility of traffic light labelling being mandatory on all foods. There was general consensus that this system would work only if it were mandatory.

The Māori participants generally did not support the multilingual Tick logo. There was a feeling in the group that the Tick programme is not a Māori programme: 'Māori buy budget, [the Tick] doesn't speak for them'. The pyramid was not seen as significant to Māori. Participants came up with a range of options for letting people know about healthy eating including information in doctors' surgeries and through supermarkets. In supermarkets participants suggested to put healthy products into one area, information in discount coupon books and signs in the store, and the use of scanners that provide nutritional information when shopping.

\section{Samoan}

Nutrition labels and Nutrition Information Panels Only two people in the Samoan group had seen general nutrition labels on food packaging. They identified that the labels related to the nutrient content of the product. Only one participant used nutrition labels due to being on a special diet. Most based their shopping on habit, so they did not read labels when they went to the supermarket. Only two had seen the NIP label on food. The group was not accustomed to looking for information on products and did not understand the terminology used. One participant stated, 'Food labels mean nothing to us... we do not read it at all'.

\section{The National Heart Foundation Tick logo}

Three people had seen the Tick logo before, although they were not sure what it meant. These people had seen the Tick on food products but had not seen it anywhere else. Some felt that the Tick logo should be bigger so it is easier to read. No participants in this group reported using the Tick to guide their food choices. One person commented, 'Most of the food Samoan people buy does not have any Tick on it'. Some felt that if a doctor told them to buy Tick products then they would.

\section{Alternative labels}

Participants wanted images they could identify with that would symbolise a healthy body, e.g. Tana Umaga (a sporting hero of Samoan ethnicity). Samoan participants were not used to nutrition labels and so found it hard to identify a preferred label from the options given. Some preferred the Tick, provided that the community was better educated about it. Some liked the traffic light labels, as the colours are easy to interpret. Participants came up with a range of options for informing their community about healthy food. They preferred information to be distributed on the radio, via church networks, schools or hospitals and they supported the use of signs to identify healthy foods in the supermarket.

\section{Tongan}

Nutrition labels and Nutrition Information Panels

All thirteen participants had seen the NIP label on food packages. Participants identified that nutrition labels detail the nutrient contents of the product. The older Tongan participants with health problems reported using nutrition labels occasionally. Two mothers with young children reported that they try to buy some healthier foods with less saturated fat, but it would depend on whether their children would eat the products. Eight participants used nutrition labels occasionally and one never used the labels.

All agreed that they would like to buy healthier food but that it was expensive. Participants felt that nutrition labels would be easier to understand if they were in Tongan. Participants identified several problems with nutrition labels, such as the writing being hard to read and the use of technical terms that are hard to understand. Some did not have time to read nutrition labels, while others already knew what they wanted to buy when they went into the supermarket.

\section{The National Heart Foundation Tick logo}

All participants had seen the Tick logo on food packaging. Participants had also seen the Tick in television advertisements, at the doctor's surgery and the supermarket. Participants associated positive meanings with the Tick, such as 'Food that is good for you' or 'Good for your heart'. Overall the Tick was seen as easy to understand and participants liked its minimal writing. Out of this group six used the Tick occasionally, three often and four never used the Tick.

One barrier to using the Tick was cost: Tick products are perceived as being too expensive. Another barrier was that some participants did not have time to look for nutrition labels. Participants in the group with heart problems said they are conscious of the food they buy and they will buy Tick products, but only if they are cheap. Participants in this group felt that if a product carries the Tick you can eat more of it compared with a product without the Tick. Several also commented that if a product does not carry the Tick it is less healthy for you, but one recognised that if a product does not carry the 
Tick it simply means the food manufacturer does not have a contract with the NHF.

\section{Alternative labels}

Similar to the Samoan focus group, the Tongan group said they would like to see a picture of someone from their community on nutrition labels. They wanted labels to have bright colours, more pictures, less writing and be in Tongan. Of the alternative nutrition labels presented, the traffic light labels met with the most support as participants already know what the traffic light colours stand for. Overall the simple traffic light system was the favoured option; however a few participants preferred the Tick logo. There was general agreement among participants that supermarket aisles should be labelled with healthy and less healthy food sections, making it much easier to identify healthy foods. Participants also expressed the need for more education about healthy foods within the Tongan community, preferably delivered by a Tongan speaker through the churches.

\section{Discussion}

Many of the participants recognised the nutrition labels presented to them but understanding of the labels was not always good. In particular, participants tended to find the NIP technical and difficult to interpret and rarely used it. The Tick logo was generally considered simple, although there was some confusion around what the logo meant. The vast majority of Māori, Pacific and lowincome participants (all of whom were regular shoppers) did not use the Tick to assist them in their food purchasing, a significant finding when compared with NHF data suggesting that $73 \%$ of main shoppers claim to use

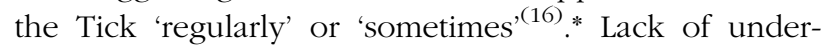
standing and knowledge about nutrition labels was a significant barrier to people using the labels.

The high price of healthy food was a recurrent theme of all focus groups. There was a widely held view that healthy food is expensive and therefore unaffordable. Many participants stated they could not afford products with the Tick because the Tick does not often appear on low-cost brands. Advocating for a reduction in the price of 'healthy food' may assist, potentially enabling these communities to purchase more food with the Tick. Further work with the food industry to improve the composition of food products, particularly low-cost products, should also be considered.

Another barrier to using nutrition labels was a lack of time, which suggests that any meaningful labelling needs to be easy and quick to understand. Habit also seems to

\footnotetext{
* Research is currently being completed by the Clinical Trials Research Unit at the University of Auckland that surveys Māori, Pacific, Asian and European New Zealanders from a range of income groups about their use of nutrition labels. This will provide further comparative evidence.
}

play an important role in supermarket shopping: many participants reported that they always buy the same foods or they buy the foods they were brought up eating. This suggests the need for social marketing and education programmes specifically developed and delivered by these communities.

Many felt that foods that did not carry the Tick logo were inferior and less healthy. The Tick programme had the unintended consequence for these people of giving them information they could not act on, a lack of selfefficacy, thus making them feel a sense of failure in a critical area of their lives ${ }^{(18)}$. Some participants recognised that the Tick is not always on 'healthy foods' (e.g. it is on some low-fat ice cream and pies), and so were sceptical about whether the Tick is actually meaningful.

Many participants wanted more information about healthy foods and how to interpret nutrition labels. This suggests a need for social marketing and education programmes developed and delivered by ethnic-specific community providers ${ }^{(19)}$. The supermarket could prove a good site for health promotion. Many participants wanted signage in supermarkets indicating healthy food sections. Samoan participants preferred information on the radio, via church networks, schools and hospitals. However, education or social marketing programmes are unlikely to be hugely successful for these communities unless other barriers such as the perceived high cost of healthy foods are addressed.

The present research provides some evidence about perceptions of possible alternative labelling systems. There was overwhelming support for a simple, colourful label that could be easily recognised. Tongan and Samoan participants suggested the label include a picture of someone from their community. If words were used there was a call for multilingual words, in all but the Māori group. Māori participants did not support using Māori language on the Tick label as they did not see it as a Māori programme and it was not on the food they buy. Multilingual labels may not accord with the desire for simplicity expressed above.

The traffic light system received significantly more support than the Tick or the pyramid, largely because it was easily understood. If the multiple traffic light labelling system were to be used in New Zealand there could be issues with understanding technical terms, especially 'saturates'. Also, if the traffic light system was to be adopted it would require a targeted social marketing and health education campaign focused on Māori, Pacific and low-income New Zealanders who currently do not use labels as part of their food purchasing behaviour. It is critical that any food labelling system includes low-cost brands of food if these communities are to benefit. A simple and easily recognisable visual system, such as traffic lights, could be mandatory on all packaged food, just as the NIP is now.

Greater involvement by Māori, Pacific and low-income communities in nutrition labelling programme planning 
and decision-making is likely to increase the effectiveness of such programmes. Working with communities to address their needs leads to greater programme success than imposing an agenda on them ${ }^{(20)}$. The greater community involvement the greater the impact and sustainability of health promotion efforts ${ }^{(21)}$.

\section{Conclusion}

Māori and Pacific people, as well as people living in poverty, have poorer nutritional health ${ }^{(1,7)}$ and stand to benefit most from effective nutrition labelling. The current research highlights that present nutrition labelling in New Zealand is failing to effectively deliver information to Māori, Pacific and low-income New Zealanders. Given the impact of nutrition-related illness in these communities, further research is urgently required to develop nutrition labelling systems that can better meet their needs. This paper suggests a number of ways forward such as targeted social marketing and education campaigns, increasing the number of low-cost foods with voluntary nutrition labels, a reduction in the price of 'healthy' food, and consideration of an alternative mandatory nutrition labelling system that uses simple imagery like traffic lights. These strategies will likely benefit Māori, Pacific and low-income communities and others who suffer the burden of similar inequalities in other regions.

\section{Acknowledgements}

The authors wish to thank the participants in this research for so willingly sharing their thoughts and feelings about the issues we discussed. We would also like to thank the members of the research advisory committee for their wise counsel. Finally our thanks go to the anonymous reviewers for their insightful comments.

Source of funding: This research was funded by the National Heart Foundation of New Zealand (NHF) (Grant 1113) to evaluate the effectiveness of the Tick Programme in Māori, Pacific and low-income communities. The research findings have been used by the NHF to develop a communications programme to improve the relevancy and use of the Tick within Māori and Pacific communities. The NHF is also working collaboratively with food manufacturers on several projects to provide healthier choices for low-cost foods. Successes have included measurable salt reductions in low-cost breads.

Conflict of interest declaration: None declared.

Authorship responsibilities: L.S. led the research project and participated in all phases of this study, including conceptualisation, design and analysis, and manuscript preparation. T.L. participated in conceptualising the study design, conducted the Tongan focus group and its analysis, participated in the overall analysis, and collaborated on the manuscript preparation. J.-A.R. participated in conceptualising of the study design, conducted the Māori and low-income focus groups and their analysis, participated in the overall analysis, and collaborated on the manuscript preparation. A.T. participated in conceptualisation of the study design, conducted the Samoan focus group and its analysis, participated in the overall analysis, and collaborated on the manuscript preparation. J.W. provided research assistance in all phases of the study, including conceptualisation, design and analysis, and took the lead in manuscript preparation. C.N.M. provided advice throughout the study as a member of the advisory committee, undertook a literature review that underpins the research and included key findings in the manuscript, and collaborated on the manuscript preparation.

\section{References}

1. Ministry of Health \& University of Auckland (2003) Nutrition and the Burden of Disease: New Zealand 1997-2011. Wellington: Ministry of Health.

2. Stefanogiannis N, Lawes CM, Turley M, Tobias M, Hoorn SV, Mhurchu CN \& Rodgers A (2005) Nutrition and the burden of disease in New Zealand: 1997-2011. Public Health Nutr 8, 395-401.

3. Lawes CMM, Stefanogiannis N, Tobias M, Paki Paki N, Ni Mhurchu C, Turley M, Vander Hoorn S \& Rodgers A (2006) Ethnic disparities in nutrition-related mortality in New Zealand, 1997-2011. N Z Med J 119, U2122.

4. Ministry of Health (2005) The Health of Pacific Peoples. Wellington: Ministry of Health.

5. Asian Public Health Project Team (2003) Asian Public Health Project Report. Wellington: Ministry of Health.

6. Ministry of Health (2003) Decades of Disparity: Ethnic Mortality Trends in New Zealand 1980-1999. Wellington: Ministry of Health.

7. Ministry of Health (2005) Decades of Disparity II: Socioeconomic Mortality Trends in New Zealand, 1981-1999. Wellington: Ministry of Health.

8. Cowburn G \& Stockley L (2005) Consumer understanding and use of nutrition labelling: a systematic review. Public Health Nutr 8, 21-28.

9. Ni Mhurchu C (2006) Nutrition Labelling: A Scientific Review Of Consumer Use and Understanding of Nutrition Labels and Claims. Auckland: University of Auckland.

10. Lang JE, Mercer N, Tran D \& Mosca L (2000) Use of a supermarket shelf-labeling program to educate a predominately minority community about foods that promote heart health. J Am Diet Assoc 100, 804-809.

11. Satia JA, Galanko JA \& Neuhouser ML (2005) Food nutrition labels use is associated with demographic, behavioral, and psychosocial factors and dietary intake among African Americans in North Carolina. J Am Diet Assoc 105, 392-402.

12. McArthur L, Chamberlain V \& Howard AB (2001) Behaviors, attitudes, and knowledge of low-income consumers regarding nutrition labels. J Health Care Poor Underserved 12, 415-428.

13. Sullivan AD (2003) Determining how low-income food shoppers perceive, understand, and use food labels. Can J Diet Pract Res 64, 25-30.

14. Bhargava A (2004) Socio-economic and behavioural factors are predictors of food use in the National Food Stamp Program Survey. Br J Nutr 92, 497-506. 
15. Young L \& Swinburn B (2002) Impact of the Pick the Tick food information programme on the salt content of food in New Zealand. Health Promot Int 17, 13-19.

16. National Heart Foundation (2005) Consumer Market Research Key Findings, Tracking Study - Heart Foundation Tick Program: Consumer Awareness, Usage, Behaviour. Auckland: NHF.

17. National Heart Foundation (2006) 10 Hip Hip Hoorays for Tick - Improving NZ Foods for 10 years. Auckland: NHF.

18. Bandura A (1986) Social Foundations of Thought and Action: A Social Cognitive Theory. New Jersey: Prentice-Hall.
19. Te Hotu Manawa Māori (2006) Kai Tōtika Me Whakapakari Tinana Nutrition and Physical Activity. http://www. tehotumanawa.org.nz/ (accessed December 2006).

20. Minkler M \& Wallerstein N (1997) Improving health through community organization and community building: a health education perspective. In Community Organizing \& Community Building for Health, pp. 30-52. [Minkler M, editor]. New Brunswick, NJ: Rutgers University Press.

21. Gillies P (1998) Effectiveness of alliances and partnerships for health promotion. Health Promot Int 13, 199-206. 